\title{
Min Max Model Predictive Control for Polysolenoid Linear Motor
}

\author{
Nguyen Hong Quang ${ }^{1}$, Nguyen Phung Quang ${ }^{2}$, Nguyen Nhu Hien ${ }^{3}$, Nguyen Thanh Binh ${ }^{4}$ \\ ${ }^{1,3}$ Department of Automation, Thai Nguyen University of Technology, Viet Nam \\ ${ }^{2}$ Institute for Control Engineering and Automation, Hanoi University of Science and Technology, Viet Nam \\ ${ }^{4}$ University of Ulsan, Korea
}

\begin{tabular}{l} 
Article Info \\
\hline Article history: \\
Received Jun 3, 2018 \\
Revised Sep 6, 2018 \\
Accepted Sep 14, 2018 \\
\hline Keyword: \\
Min max model predictive \\
Control \\
Polysolenoid linear motor \\
Permanent magnet linear \\
Synchronous motor
\end{tabular}

\begin{abstract}
The Polysolenoid Linear Motor (PLM) have been playing a crucial role in many industrial aspects because it provides a straight motion directly without mediate mechanical actuators. Some control methods for PLM based on Rotational Motor are applied to obtain several good performances, but position and velocity constraints which are important in real systems are ignored. In this paper, we analysis control problem of tracking position in PLM under state-independent disturbances via min-max model predictive control. The proposed controller brings tracking position error converge to zero and satisfies state including position and velocity and input constraints. The simulation results validity a good efficiency of the proposed controller.
\end{abstract}

Copyright $(2018$ Institute of Advanced Engineering and Science. All rights reserved.

\section{Corresponding Author:}

Nguyen Hong Quang, Department of Automation, Thai Nguyen University Of Technology, 666, 3/2 Street, Tich Luong ward, Thai Nguyen city, Viet Nam.

Email: quang.nguyenhong@tnut.edu.vn (nhquang.tnut@gmail.com)

\section{INTRODUCTION}

Linear Motor transmission systems are widely applied to provide directed straight motions in which, mechanical actuators are eliminated, resulting in better performance of motion systems. Generally, polysolenoid linear motor (PLM) has a durable structure [1], operations according to electromagnetic phenomenon with principles as shown in [2]-[6] and various applications such as CNC Lathe [7], sliding door [8]. Without the need of any gear box for motion transformation, the PLM system becomes sensitive due to external impacts such as frictional force, end - effect, changed load and non-sine of flux. These effects encounter both in the longitudinal and in the transversal direction, which along with saturation in supplied voltage make obtaining good control performance from the linear drive a difficult task.

There are several researches taking into account the position control of PLM in presence of external disturbances. The authors in [9] presented a control design method to regulate velocity based on PI selftunning combining with appropriate estimation technique at slow velocity zone, but if load is changed, PI - selftunning controller will be not efficient. In order to overcome changed load, model reference control method based on Lyapunov stability theory was employed in [10]. Additionally, the compensation approaches were proposed in researches [11],[12] in which, the frictional force were estimated by Lugrie and Stribeck friction model respectively. In [13], the advantage of that the sliding mode control applied in Linear Motor is that real position value tracks set point. However, the disadvantages of this method are finding sliding surface and chattering. In the view of nonlinear systems, the study in [14],[15] apply linearization method to PLM system but this method is restricted by uncertain parameter and disturbances. The authors in [16] built a new mathematic model and use optimal control approach to result in linear quadratic regulation 
(LQR). It is clear that the previous researches do not mention position, velocity and currents constraints as well as impact of external disturbance which is important properties of the control systems.

The contribution of this study is to develop a position control system for PLM in which, the the proposed control structure is based on separating a dynamic model into two subsystem including positionvelocity and current. The output of position-velocity controller is reference of current control-ler. The position controller is designed based on a min-max model predictive control theory in [17] to ensure that position and velocity error being in their constraints and converging to a small ball neighborhood of origin under state-independent disturbance. The current controller is designed based on a PI-controller with crosscurrent compensation method.

\section{DYNAMIC MODEL}

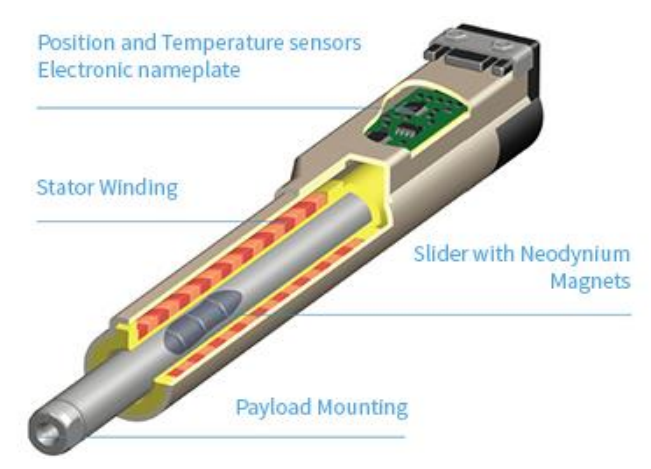

Figure 1. Composition of Polysolenoid motor [1]

Let us consider a dynamic model of PLM in [14],[15],[18]

$$
\begin{aligned}
& \frac{d i_{s d}}{d t}=-\frac{R_{s}}{L_{s d}} i_{s d}+\left(\frac{2 \pi p}{\tau} v\right) \frac{L_{s q}}{L_{s d}} i_{s q}+\frac{u_{s d}}{L_{s d}} \\
& \frac{d i_{s q}}{d t}=-\frac{R_{s}}{L_{s q}} i_{s q}-\left(\frac{2 \pi}{\tau} v\right) \frac{L_{s d}}{L_{s q}} i_{s d}-\left(\frac{2 \pi p}{p \tau} v\right) \frac{\psi_{p}}{L_{s q}}+\frac{u_{s q}}{L_{s q}} \\
& \frac{d v}{d t}=\frac{2 \pi p}{\tau}\left(\psi_{p}+\left(L_{s d}-L_{s q}\right) i_{s d}\right) i_{s q}-\frac{1}{m} F_{c}, \\
& \frac{d x}{d t}=v .
\end{aligned}
$$

where $i_{s d}, i_{s q}, v, x$ are current, velocity and position respectively, $R_{s}$ is resistance, $L_{s d}, L_{s q}$ is inductor $p$ is pole pair $\tau$ is pole step $U_{s d}, U_{s q}$ is voltage $\psi_{p}$ is flux $m$ is massive $F_{c}$ is unmeasured external force.

In the dynamic model (1) is same as that of permanent magnet rotation synchronization motor. When it comes to PLM, $L_{s d}, L_{s q}$ have the approximate similar values and reference current $i_{s d r}=0$ in the current controller; therefore, term $\left(L_{s d}-L_{s q}\right) i_{s d} i_{s q}$ can be ignored in the third equation in (1), leading to that current $i_{s q}$ relates position-velocity by linear equations.

\section{PROPOSED METHOD}

In this paper, let us separate dynamic model (1) into current subsystem and position-velocity subsystem. The previous chapter shows position subsystem can be considered as a linear system and applied algorithm in [17]. In current subsystem, the proposed method is cross-current compensation method between $i_{s d}, i_{s q}$ to change dynamic model to a linear state space model to apply a controller based on PI - controller.

\subsection{Control of current - subsystem}


Applying decoupling control:

$$
\begin{aligned}
& u_{s d}=-\left(\frac{2 \pi p}{\tau} v\right) L_{s q} i_{s q}+u_{1}, \\
& u_{s q}=\left(\frac{2 \pi p}{\tau} v\right) L_{s d} i_{s d}+\left(\frac{2 \pi p}{p \tau} v\right) \psi_{p}+u_{2} .
\end{aligned}
$$

Current systems is transformed to:

$$
\begin{aligned}
& \frac{d i_{s d}}{d t}=-\frac{R_{s}}{L_{s d}} i_{s d}+\frac{u_{1}}{L_{s d}}, \\
& \frac{d i_{s q}}{d t}=-\frac{R_{s}}{L_{s q}} i_{s q}+\frac{u_{2}}{L_{s q}} .
\end{aligned}
$$

Using current controller (PI controller):

$$
\begin{aligned}
& u_{1}=L_{s d} \frac{d}{d t} i_{s d}^{r}+\frac{R_{s}}{L_{s d}} i_{s d}+L_{s d}\left(k_{11} i_{s d}^{e}+k_{12} \int_{0}^{t} i_{s d}^{e}(\tau) d \tau\right), \\
& u_{2}=L_{s q} \frac{d}{d t} i_{s q}^{r}+\frac{R_{s}}{L_{s q}} i_{s q}+L_{s q}\left(k_{21} i_{s q}^{e}+k_{22} \int_{0}^{t} i_{s q}^{e}(\tau) d \tau\right),
\end{aligned}
$$

where $i_{s d}^{e}=i_{s d}^{r}-i_{s d} ; i_{s q}^{e}=i_{s q}^{r}-i_{s q} \cdot$ We obtain current closed loop:

$$
\begin{aligned}
& \frac{d i_{s d}^{e}}{d t}+k_{11} i_{s d}^{e}+k_{12} \int_{0}^{t} i_{s d}^{e}(\tau) d \tau=0 \\
& \frac{d i_{s q}^{e}}{d t}+k_{12} i_{s q}^{e}+k_{22} \int_{0}^{t} i_{s q}^{e}(\tau) d \tau=0
\end{aligned}
$$

By turning coefficients $k_{11}, k_{12}, k_{21}, k_{22}$, the controller (4) guarantee global exponential stability of closed loop (5).

Remark 1: The current reference $i_{s d}^{r}=0$ and coefficients $k_{11}, k_{12} k_{21}, k_{22}$ is choosen such that closed loop (5) become undamped second order system and its transient time is small than horizon prediction in position subsystems.

\subsection{Control of Position-Velocity subsystem}

The dynamic of position subsystem is significantly slower than current subsystems. In the control design of position, we assumed that the desired current equals to actual current. From (1) and remark 1, we have model of position system

$$
\begin{aligned}
& \frac{d x}{d t}=v, \\
& \frac{d v}{d t}=\frac{2 p p}{t m} y_{p} i_{s q}-\frac{1}{m} F_{c} .
\end{aligned}
$$

The equation (6) can be rewrite in state space model of tracking errors by setting $i_{s q}=u+\frac{m \tau}{2 \pi p \psi_{p}} \ddot{x}_{r}$

$$
\begin{aligned}
& \frac{d \mathbf{z}}{d t}=\mathbf{A z}+\mathbf{B} u+\mathbf{H} d, \\
& y=\mathbf{C z},
\end{aligned}
$$


where

$$
\begin{aligned}
& e_{x}=x-x_{r}, e_{v}=v-v_{r}, \\
& \mathbf{z}=\left[e_{x}, e_{v}\right], d=F_{c}, \mathbf{C}=[1,0], \\
& \mathbf{A}=\left[\begin{array}{ll}
0 & 1 \\
0 & 0
\end{array}\right], \mathbf{B}=\left[\begin{array}{c}
0 \\
\frac{2 \pi p}{m \tau} \psi_{p}
\end{array}\right], \mathbf{D}=\left[\begin{array}{c}
0 \\
-\frac{1}{m}
\end{array}\right] .
\end{aligned}
$$

To obtain a discrete state space model, let us apply the forward Euler method to equation (7)

$$
\begin{aligned}
& \mathbf{z}_{k+1}=\mathbf{A}_{d} \mathbf{z}_{k}+\mathbf{B}_{d} u_{k}+\mathbf{D}_{d} d_{k}, \\
& y_{k}=\mathbf{C} \mathbf{z}_{k} .
\end{aligned}
$$

Control Objective:

$$
\begin{aligned}
& \mathbf{z}_{k} \in \mathbf{Z}, u_{k} \in \mathbf{U}, \\
& \mathbf{z}_{k} \rightarrow \mathbf{Z}_{0} \in \mathbf{Z},
\end{aligned}
$$

where

$$
\begin{aligned}
& \mathbf{Z}_{0} \square\left\{\left(z_{1}, z_{2}\right) \in \square^{2} \mid e_{0 x \min }<z_{1}<e_{0 x \max }, e_{0 v \min }<z_{2}<e_{0 v \max }\right\}, \\
& \mathbf{Z}_{0} \in \mathbf{Z} \square\left\{\left(z_{1}, z_{2}\right) \in \square^{2} \mid e_{x \min }<z_{1}<e_{x \max }, e_{v \min }<z_{2}<e_{v \max }\right\}, \\
& \mathbf{U} \square\left(U_{\min }, U_{\max }\right) \in \square .
\end{aligned}
$$

To achieve control objective (10), we use min-max model predictive control proposed in (1)-(6). In position controller, we consider a dual-mode control law: an "inner" and an "outer" controller. The inner controller is active when the state is in the robust control invariant set $\mathbf{Z}_{0}$, and its role is to keep the state in this set under external disturbance $F_{c}$. The outer controller operates when the state is outside the invariant set and steers the system state to the invariant set $\mathbf{Z}_{0}$.

The inner controller we use is linear feedback $u_{k}=\mathbf{K} \mathbf{z}_{k}$ which is obtained by different way in compare with [17]. This property of the inner controller is important in the construction of the control robust invariant set. For the outer controller, we use min-max MPC, which form the focus of this paper and consider a fixed horizon formulation.

Algorithm 1:

Data: $\mathbf{z}_{k}$

If $\mathbf{z}_{k} \in \mathbf{Z}_{0}$, set $u_{k}=\mathbf{K} \mathbf{z}_{k}$. Otherwise, find the solution of (12) and set $\mathbf{u}_{k}$ to the first control in the optimal sequence calculated.

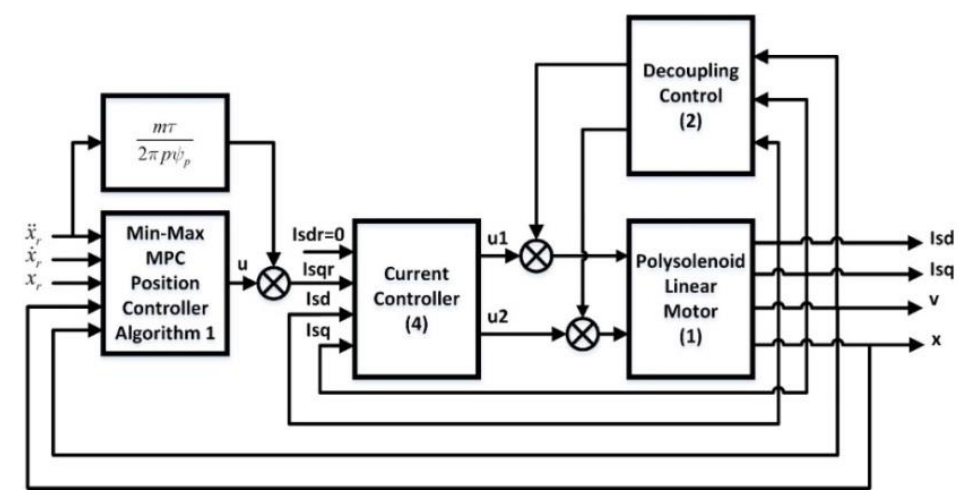

Figure 2. Control Structure 


\subsubsection{Design of inner controller}

In research [6], the robust control invariant set $\mathbf{Z}_{0}$ is selected as simple based on propoerty $(\mathbf{A}-\mathbf{B K})^{s}=0, \mathrm{~s}$ is a positive integer number and $\mathbf{Z}_{0}=\sum_{1}^{s}(\mathbf{A}-\mathbf{B K})^{s} \mathbf{W}$ with $d \in \mathbf{W}$. In this selection, set $\mathbf{Z}_{0}$ is not evaluated to be arbitrarily small to ensuare the performances of system. Moreover in some cases, we can not found $\mathbf{K}$ such that $(\mathbf{A}-\mathbf{B K})^{s}=0$ hold for any s. In this subchapter, $\mathbf{Z}_{0}$ and matrix $\mathbf{K}$ is found based on Lyapunov's direct method and LMIs technique

$$
\begin{aligned}
& V\left(\mathbf{z}_{k}\right)=\mathbf{z}_{k}^{T} \mathbf{P} \mathbf{z}_{k}, \mathbf{P}=\mathbf{P}^{T}>0, \\
& V\left(\mathbf{z}_{k}\right)-V\left(\mathbf{z}_{k+1}\right)=\mathbf{z}_{k}^{T} \mathbf{P} \mathbf{z}_{k}-\left(\mathbf{A}_{d} \mathbf{z}_{k}+\mathbf{B}_{d} u_{k}+\mathbf{D}_{d} d_{k}\right)^{T} \mathbf{P}\left(\mathbf{A}_{d} \mathbf{z}_{k}+\mathbf{B}_{d} u_{k}+\mathbf{D}_{d} d_{k}\right) .
\end{aligned}
$$

Substituting $u_{k}=\mathbf{K} \mathbf{z}_{k}$ into equation (12) we have

$$
\begin{aligned}
& V\left(\mathbf{z}_{k}\right)-V\left(\mathbf{z}_{k+1}\right)=\mathbf{z}_{k}^{T} \mathbf{P} \mathbf{z}_{k}-\left(\left(\mathbf{A}_{d}+\mathbf{B}_{d} \mathbf{K}\right) \mathbf{z}_{k}+\mathbf{D}_{d} d_{k}\right)^{T} \mathbf{P}\left(\left(\mathbf{A}_{d}+\mathbf{B}_{d} \mathbf{K}\right) \mathbf{z}_{k}+\mathbf{D}_{d} d_{k}\right) \\
& =\mathbf{z}_{k}^{T}\left(\mathbf{P}-\left(\mathbf{A}_{d}+B_{d} \mathbf{K}\right)^{T} \mathbf{P}\left(\mathbf{A}_{d}+\mathbf{B}_{d} \mathbf{K}\right)\right) \mathbf{z}_{k}-2 \mathbf{z}_{k}^{T}\left(\mathbf{A}_{d}+\mathbf{B}_{d} \mathbf{K}\right)^{T} \mathbf{P} \mathbf{D}_{d} d_{k}-\mathbf{D}_{d}^{T} \mathbf{P} \mathbf{D}_{d} d_{k}^{2}, \\
& \geq \mathbf{z}_{k}^{T}\left(\mathbf{P}-\left(\mathbf{A}_{d}+\mathbf{B}_{d} \mathbf{K}\right)^{T} \mathbf{P}\left(\mathbf{A}_{d}+\mathbf{B}_{d} \mathbf{K}\right)\right) \mathbf{z}_{k}-\mathbf{z}_{k}^{T} \gamma\left(\mathbf{A}_{d}+\mathbf{B}_{d} \mathbf{K}\right)^{T} \mathbf{P}\left(\mathbf{A}_{d}+\mathbf{B}_{d} \mathbf{K}\right) \mathbf{z}_{k}-\left(1+\frac{1}{\gamma}\right) \mathbf{D}_{d}^{T} \mathbf{P} \mathbf{D}_{d} d_{\max }^{2}
\end{aligned}
$$

With asumption that the disturbance is bounded: $|d| \leq d_{\max }$, we take the following matrix inequalities

$$
\begin{aligned}
& \mathbf{P}-(\gamma+1)\left(\mathbf{A}_{d}+\mathbf{B}_{d} \mathbf{K}\right)^{T} \mathbf{P}\left(\mathbf{A}_{d}+\mathbf{B}_{d} \mathbf{K}\right) \geq \mathbf{M}, \\
& \mathbf{M}=\operatorname{diag}\left[q_{1}, q_{2}\right]>0 \\
& V\left(\mathbf{z}_{k}\right)-V\left(\mathbf{z}_{k+1}\right) \geq \mathbf{z}_{k}^{T} \mathbf{M z}_{k}-\left(1+\frac{1}{\gamma}\right) \mathbf{D}_{d}^{T} \mathbf{P D}_{d} d_{\text {max }}^{2}=q_{1} z_{k 1}^{2}+q_{2} z_{k 2}^{2}-\left(1+\frac{1}{\gamma}\right) \mathbf{D}_{d}^{T} \mathbf{P D}_{d} d_{\text {max }}^{2} .
\end{aligned}
$$

The robust control invariant set can be choosen as

$$
\mathbf{Z}_{0} \square\left\{\mathbf{z}_{k}=\left(z_{k 1}, z_{k 2}\right) \in \square^{2}:\left|\mathbf{z}_{k 1}\right|<d_{\max } \sqrt{\frac{(1+1 / \gamma) \mathbf{D}_{d}^{T} \mathbf{P} \mathbf{D}_{d}}{q_{1}}},\left|\mathbf{z}_{k 2}\right|<d_{\max } \sqrt{\frac{(1+1 / \gamma) \mathbf{D}_{d}^{T} \mathbf{P D}_{d}}{q_{2}}}\right\},
$$

Letting $U_{\max }$ is saturation input bounded, the matrix state feedback control $\mathbf{K}$ can be obtianed by solving matrix inequalites

$$
\begin{aligned}
& \mathbf{P}-(1+\gamma)\left(\mathbf{A}_{d}+\mathbf{B}_{d} \mathbf{K}\right)^{T} \mathbf{P}\left(\mathbf{A}_{d}+\mathbf{B}_{d} \mathbf{K}\right) \geq \mathbf{M} \\
& \left|\mathbf{K} \mathbf{z}_{k}\right| \leq U_{\max }, \\
& \mathbf{P}^{-1}-(1+\gamma)\left(\mathbf{A}_{d} \mathbf{P}^{-1}+\mathbf{B}_{d} \mathbf{K} \mathbf{P}^{-1}\right)^{T} \mathbf{P}\left(\mathbf{A}_{d} \mathbf{P}^{-1}+\mathbf{B}_{d} \mathbf{K} \mathbf{P}^{-1}\right)-\mathbf{P}^{-1} \mathbf{M} \mathbf{P}^{-1} \geq 0
\end{aligned}
$$

Setting $\mathbf{P}^{-1}=\mathbf{T}, \mathbf{K} \mathbf{P}^{-1}=\mathbf{L}, \mathbf{M}^{-1}=\operatorname{diag}\left(\left[m_{1}, \mathrm{~m}_{2}\right]\right)$, the inequalites (18) is converted to LMIs problem

$$
\operatorname{Max}_{\mathbf{T}, \mathbf{L}, m_{1}, m_{2}, \lambda, \xi} \xi
$$

Subject to 


$$
\begin{aligned}
& \mathbf{T}=\mathbf{T}^{T}>0, m_{1}>0, \mathrm{~m}_{2}>0, \lambda>0, \\
& {\left[\begin{array}{cc}
m_{1} & \lambda \\
\lambda & \xi
\end{array}\right]<0,} \\
& {\left[\begin{array}{cc}
\mathbf{T} & \lambda \mathbf{I} \\
\lambda \mathbf{I} & \mathbf{I}
\end{array}\right]>0,} \\
& {\left[\begin{array}{ccc}
\mathbf{T} & \left(\mathbf{A}_{d} \mathbf{T}+\mathbf{B}_{d} \mathbf{L}\right)^{T} & \mathbf{T} \\
\mathbf{A}_{d} \mathbf{T}+\mathbf{B}_{d} \mathbf{L} & (1+\gamma)^{-1} \mathbf{T} & 0 \\
\mathbf{T} & 0 & \mathbf{M}^{-1}
\end{array}\right] \geq 0,} \\
& \left.\begin{array}{ccc}
U_{\max }^{2} \lambda^{2} & \left(\mathbf{L} \mathbf{z}_{k}\right)^{T} \\
\mathbf{L} z_{k} & \mathbf{P}
\end{array}\right] \leq 0 .
\end{aligned}
$$

Remark 2: The optimization problem via LMIs (19) with constraints (20-24) can be solved by interior point with YALMIP toolbox. In that, $\xi^{-1}$ is ball bounding origin and it is minimized when $\xi$ is selected as maximum.

\subsubsection{Design of outer controller}

In this section, we consider quadratic cost function as

$$
\begin{aligned}
& L(\underline{\mathbf{z}}, \underline{\mathbf{u}})=\sum_{i=0}^{N-1}\left(\mathbf{z}_{k+i}^{T} \mathbf{Q} \mathbf{z}_{k+i}+\mathbf{u}_{k+i}^{T} \mathbf{R} \mathbf{u}_{k+i}\right), \\
& \mathbf{Q} \geq 0, \mathbf{R}>0 .
\end{aligned}
$$

Min - max optimization

$$
\begin{aligned}
& J=\min _{u_{k} \in U} \max _{d_{k} \in D} L(\underline{\mathbf{z}}, \underline{\mathbf{u}}), \\
& \text { s.t., } \\
& \mathbf{z}_{k+i+1}=\mathbf{A}_{d} \mathbf{z}_{k+i}+\mathbf{B}_{d} \mathbf{u}_{k+i}+\mathbf{D}_{d} d_{k+i}, \\
& \mathbf{z}_{k+i} \in \mathbf{Z} \quad 0<i<N, \\
& \mathbf{z}_{k+N} \in \mathbf{Z}_{0},
\end{aligned}
$$

where:

$$
\begin{aligned}
& \underline{\mathbf{z}}=\left[\mathbf{z}_{k}, \mathbf{z}_{k+1}, \ldots, \mathbf{z}_{k+N-1}\right]^{T}, \\
& \underline{\mathbf{u}}=\left[u_{k}, u_{k+1}, \ldots, u_{k+N-1}\right]^{T}, \\
& \underline{\mathbf{d}}=\left[d_{k+1}, d_{k+2}, \ldots, d_{k+N-1}\right]^{T} .
\end{aligned}
$$

By setting:

$$
\begin{aligned}
& \mathbf{D}_{i}=\left[\mathbf{A}_{d}^{i-1} \mathbf{D}_{d}, \mathbf{A}_{d}^{i-2} \mathbf{D}_{d}, \ldots, \mathbf{D}_{d}, \mathbf{O}, \ldots \mathbf{O}\right], \mathbf{D}_{i} \in R^{2 \times N}, \\
& \mathbf{B}_{i}=\left[\mathbf{A}_{d}^{i-1} \mathbf{B}_{d}, \mathbf{A}_{d}^{i-2} \mathbf{B}_{d}, \ldots, \mathbf{B}_{d}, \mathbf{O}, \ldots \mathbf{O}\right], \mathbf{B}_{i} \in R^{2 \times N}
\end{aligned}
$$

We have: 


$$
\mathbf{z}_{k+i}=\mathbf{A}_{d}^{i} \mathbf{z}_{k}+\mathbf{B}_{i} \underline{\mathbf{u}}+\mathbf{D}_{i} \underline{\mathbf{d}}
$$

Substituting (27) into (28) and rewriting in quadratic form (35)

$$
\begin{aligned}
L(\underline{\mathbf{z}}, \underline{\mathbf{u}}) & =\underline{\mathbf{d}}^{T}\left(\sum_{i=1}^{N-1} \mathbf{D}_{i}^{T} \mathbf{Q} \mathbf{D}_{i}\right) \underline{\mathbf{d}}+\underline{\mathbf{u}}^{T}\left(\operatorname{diag}([\mathbf{R} \ldots . . \mathbf{R}])+\sum_{i=1}^{N-1} \mathbf{B}_{i}^{T} \mathbf{Q} \mathbf{B}_{i}\right) \underline{\mathbf{u}} \\
& +2 \mathbf{z}_{k}^{T}\left(\sum_{i=1}^{N-1}\left(\mathbf{A}_{d}^{i}\right)^{T} \mathbf{Q} \mathbf{D}_{i}\right) \underline{\mathbf{d}}+\sum_{i=0}^{N-1} \mathbf{z}_{k}^{T}\left(\mathbf{A}_{d}^{i}\right)^{T} \mathbf{Q} \mathbf{A}_{d}^{i} \mathbf{z}_{k}+\left(\sum_{i=1}^{N-1}\left(2 \mathbf{z}_{k}^{T}\left(\mathbf{A}_{d}^{i}\right)^{T} \mathbf{Q} \mathbf{B}_{i}+2 \underline{\mathbf{d}}^{T} \mathbf{D}_{i}^{T} \mathbf{Q} \mathbf{B}_{i}\right)\right) \underline{\mathbf{u}} .
\end{aligned}
$$

Putting the constraints in (26) into linear inequality form by bounded interval representing for robust control invariant set

$$
\begin{aligned}
& \mathbf{Z}_{\text {min }}=\left[e_{x \min }, e_{v \min }\right], \mathbf{Z}_{\max }=\left[e_{x \max }, e_{v \max }\right], \\
& \mathbf{Z}_{0 \text { min }}=\left[e_{0 x \min }, e_{0 \min }\right], \mathbf{Z}_{0 \text { max }}=\left[e_{0 x \max }, e_{0 v \max }\right] .
\end{aligned}
$$

We rewrite the constraints in (26) in linear forms. State constraints

$$
\begin{aligned}
& \mathbf{Z}_{\min } \leq \mathbf{z}_{k+i} \leq \mathbf{Z}_{\max }, \quad(1 \leq i \leq N-1) \\
\Leftrightarrow & \mathbf{Z}_{\min } \leq \mathbf{A}_{d}^{i} \mathbf{z}_{k}+\mathbf{B}_{i} \underline{\mathbf{u}}+\mathbf{D}_{i} \underline{\mathbf{d}} \leq \mathbf{Z}_{\max } \\
\Leftrightarrow & \mathbf{Z}_{\min }-\mathbf{A}_{d}^{i} \mathbf{z}_{k}-\mathbf{D}_{i} \underline{\mathbf{d}} \leq \mathbf{B}_{i} \underline{u} \leq \mathbf{Z}_{\max }-\mathbf{A}_{d}^{i} \mathbf{z}_{k}-\mathbf{D}_{i} \underline{d} \\
\Leftrightarrow & {\left[\begin{array}{c}
\mathbf{B}_{i} \\
-\mathbf{B}_{i}
\end{array}\right] \underline{\mathbf{u}} \leq\left[\begin{array}{c}
\mathbf{Z}_{\max }-\mathbf{A}_{d}^{i} \mathbf{z}_{k}-\mathbf{D}_{i} \underline{\mathbf{d}} \\
-\mathbf{Z}_{\min }+\mathbf{A}_{d}^{i} \mathbf{z}_{k}+\mathbf{D}_{i} \underline{\mathbf{d}}
\end{array}\right] }
\end{aligned}
$$

Terminal state constraints

$$
\begin{aligned}
& \mathbf{Z}_{0 \min } \leq \mathbf{z}_{k+N} \leq \mathbf{Z}_{0 \max } \\
\Leftrightarrow & \mathbf{Z}_{0 \min } \leq \mathbf{A}_{d}^{N} \mathbf{z}_{k}+\mathbf{B}_{N} \underline{\mathbf{u}}+\mathbf{D}_{N} \underline{\mathbf{d}} \leq \mathbf{Z}_{0 \max } \\
\Leftrightarrow & \mathbf{Z}_{0 \min }-\mathbf{A}_{d}^{N} \mathbf{z}_{k}-\mathbf{D}_{N} \underline{\mathbf{d}} \leq \mathbf{B}_{i} \underline{\mathbf{u}} \leq \mathbf{Z}_{0 \max }-\mathbf{A}_{d}^{i} \mathbf{z}_{k}-\mathbf{D}_{N} \underline{\mathbf{d}} \\
\Leftrightarrow & {\left[\begin{array}{c}
\mathbf{B}_{N} \\
-\mathbf{B}_{N}
\end{array}\right] \underline{\mathbf{u}} \leq\left[\begin{array}{c}
\mathbf{Z}_{0 \max }-\mathbf{A}_{d}^{N} \mathbf{z}_{k}-\mathbf{D}_{N} \underline{\mathbf{d}} \\
-\mathbf{Z}_{0 \min }+\mathbf{A}_{d}^{N} \mathbf{z}_{k}+\mathbf{D}_{N} \mathbf{d}
\end{array}\right] }
\end{aligned}
$$

Input limitations:

$$
\left\{\begin{array}{c}
U_{\min } \leq u_{k} \leq U_{\max } \\
\cdots \\
U_{\min } \leq u_{k+N-1} \leq U_{\max }
\end{array}\right.
$$

Combining three constraints (30)-(32), we solve Min - Max optimization (26) by using QP method.

Remark 3: To make optimization problem (26) become simpler we assumption that $D=\left\{d_{k} \in D\right\}$ has limited known bounded values. For instant, $D=\left\{d_{1}, d_{2}, \ldots \ldots, d_{l}\right\}$ the convergent of $\mathbf{z}_{k}$ to robust control invariant set $\mathbf{Z}_{0}$ is guaranteed by theorem 1 in [17].

\section{RESULTS AND ANALYSIS}

In this section, we simulate the position tracking of whole system under state, input constraint and external disturbance in Table 1. We use the same current controller and two different prediction horizons of position controller to compare quality of each controller. 
Table 1. The parameter of Polysolenoid Linear Motor P01-23X80/80X140 and controller

\begin{tabular}{cc}
\hline Parameter & Value \\
\hline Pole pair & 1 \\
Pole step & $20(\mathrm{~mm})$ \\
Rotor mass & $0.17(\mathrm{~kg})$ \\
Phase coil Resistance & $10.3(\Omega)$ \\
d-axis inductance & $1.4(\mathrm{mH})$ \\
q-axis inductance & $1.4(\mathrm{mH})$ \\
Flux & $0.035(\mathrm{~Wb})$ \\
$\mathrm{K}$ (inner control) & {$[-300,-5]$} \\
{$\left[k_{11}, k_{12}, k_{21}, k_{22}\right]$} & {$[100,800,100,800]$} \\
\hline
\end{tabular}

As can be seen in Figure 3-4, at initial time both position and velocity error stay outside of state constraints region and after smaller than $0.2 \mathrm{~s}$, they converges to small ball centered at origin. The currents is satisfies input constraint under time varying external forces.

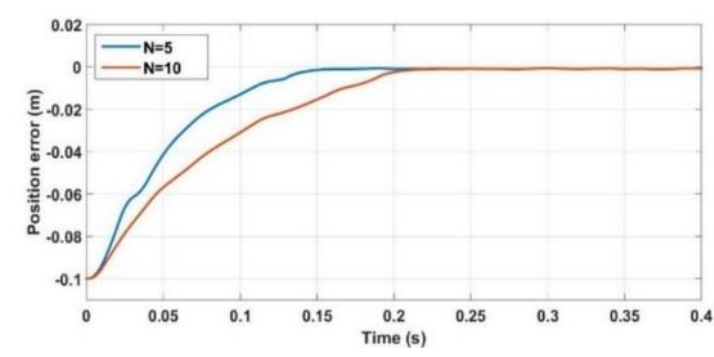

Figure 3. The time evolution of position error

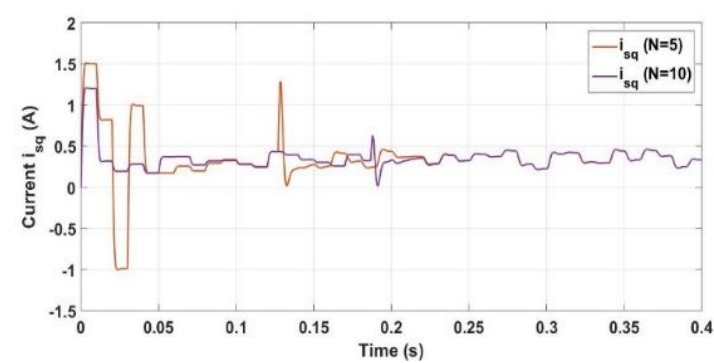

Figure 5. The time evolution of current in dq coordinates

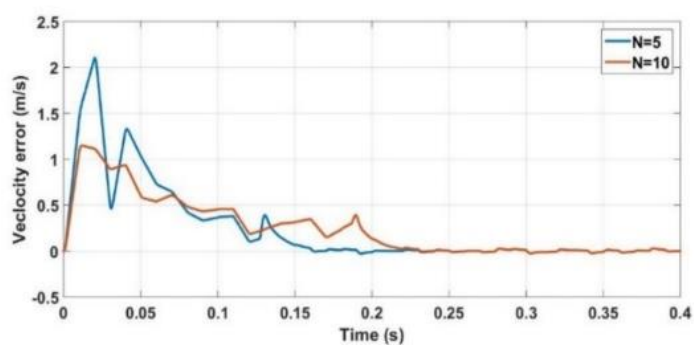

Figure 4. The time evolution of velocity error

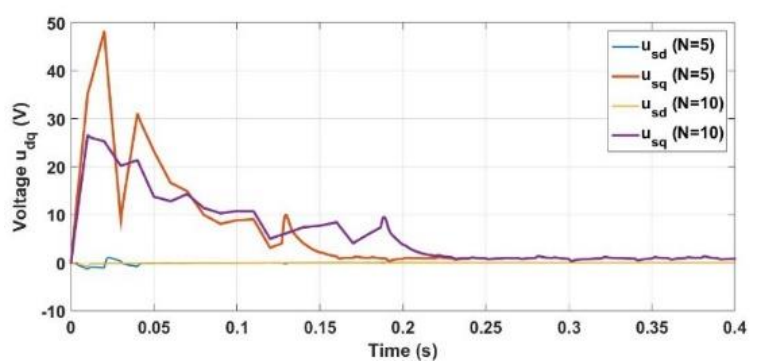

Figure 6. The time evolution of supplied voltage dqcoordinates

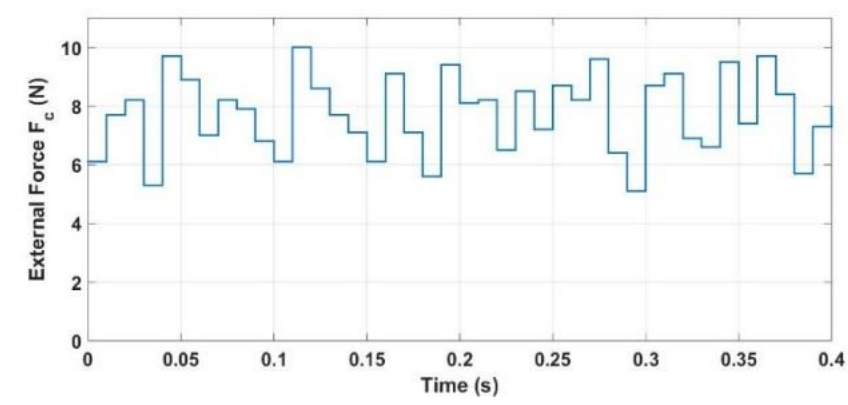

Figure 7. The time evolution of external disturbance force 


\section{CONCLUSION}

This research proposed min-max model predictive control for polysolenoid linear motor. Our method not only addressed the position tracking problem of the linear motor in the presence of external disturbance and input saturations but also stabilized closed-loop system in comparison with classical model predictive control. The good performance of control method, working properly even at high speed was demonstrated by numerical simulation. Furthermore, the min-max controller can be implemented easily to hardware by using quadratic programming method.

\section{ACKNOWLEDGEMENTS}

This research is funded by Thai Nguyen University of Technology under grant number T2017-B08.

\section{REFERENCES}

[1] www.linmot.com

[2] N. P. Quang and J. A. Dittrich, "Vector Control of Three-Phase AC Machines - System Development in the Practice," Springer Berlin Heidelberg, 2015.

[3] J. F. Gieras, et al., "Linear Synchronous Motors Transportation and Automation Systems," CRC press, 2011.

[4] I. Boldea, "Linear Electric Machines, Drives, and MAGLEVs Handbook," CRC press, 2013.

[5] D. Ausderau, "Polysolenoid - Linearantrieb mit genutetem Stator," Zurich. PhD Thessis, 2004.

[6] H. Li, et al., "Performance Assessment and Comparison of Two Types Linear Motors for Electromagnetic Catapult," TELKOMNIKA Indonesian Journal of Electrical Engineering, vol/issue: 12(4), pp. 2506-2515, 2014.

[7] Y. Zeqing, et al., "Static and Dynamic Characteristic Simulation of Feed System Driven by Linear Motor in High Speed Computer Numerical Control Lathe," TELKOMNIKA Indonesian Journal of Electrical Engineering, vol/issue: 11(7), pp. 3673-3683, 2013.

[8] A. Lachheb, et al., "Performances Analysis of a Linear Motor for Sliding Door Application," International Journal of Power Electronics and Drive System (IJPEDS), vol/issue: 8(3), pp. 1139-1146, 2017.

[9] J. K. Seok, et al., "Sensorless Speed Control of Nonsalient Permanent Magnet Synchronous Motor Using Rotor Position Tracking PI Controller," IEEE Transactions on Industrial Electronics, vol/issue: 53(2), pp.399-405, 2006.

[10] Y. R. Chen, et al., "Lyapunov's Stability Theory - Based Model Reference Adaptive Control for Permanent Magnet Linear Motor Drives," Proc of Power Electronics Systems and Application, pp. 260-266, 2004.

[11] C. I. Huang and L. C. Fu, "Adaptive Backstepping Speed Position Control with Friction Compensation for Linear Induction Motor," Proceeding of the 41st IEEE Conference on Decision and Control, pp. 474 - 479, 2002.

[12] X. Cui, et al., "A Research on Dynamic Friction Compensation of High-speed Linear motor," TELKOMNIKA Indonesian Journal of Electrical Engineering, vol/issue: 10(8), pp. 1963-1968, 2012.

[13] G. Tapia and A. Tapia, "Sliding Mode Control for Linear Permanent Magnet motor Position Tracking," Proc of the IFAC World Congress, pp. 163-168, 2005.

[14] Q. H. Nguyen, et al., "Flatness Based Control Structure for Polysolenoid Permanent Stimulation Linear Motors," SSRG International Journal of Electrical and Electronics Engineering, vol/issue: 3(12), pp. 31-37, 2016.

[15] Q. H. Nguyen, et al., "Design an Exact Linearization Controller for Permanent Stimulation Synchronous Linear Motor Polysolenoid," SSRG International Journal of Electrical and Electronics Engineering, vol/issue: 4(1), pp. 7 $12,2017$.

[16] H. Komijani, et al., "Modeling and State Feedback Controller Design of Tubular Linear Permanent Magnet Synchronous Motor," International Journal of Power Electronics and Drive System (IJPEDS), vol/issue: 7(4), pp. 1410-1419, 2016.

[17] P. O. M. Scokaert and D. Q. Mayne, "Min-Max Feedback Model Predictive Control for Constrained Linear Systems," IEEE Transactions On Automatic Control, vol/issue: 43(8), 1998.

[18] Quang N. H., et al., "Multi Parametric Programming based Model Predictive Control for tracking Control of Polysolenoid Linear Motor," Special issue on Measurement, Control and Automation, vol. 19, pp. 31-37, 2017.

\section{BIOGRAPHIES OF AUTHORS}

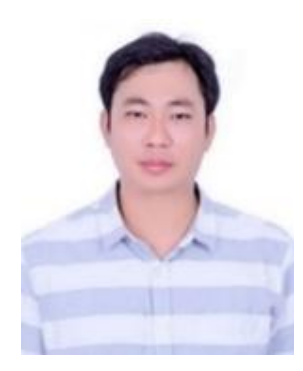

Nguyen Hong Quang received the B.S degree in electrical engineering from Thai Nguyen University of technology (TNUT), Vietnam, in 2007, the Master's degree in control engineering and automation from Hanoi University of Science and Technology (HUST), Viet Nam, in 2012. He is currently with TNUT as PhD student and Lecturer. His Research Interests are Electrical Drive Systems, Adaptive Dynamic Programming Control, Robust Nonlinear Model Predictive Control. 

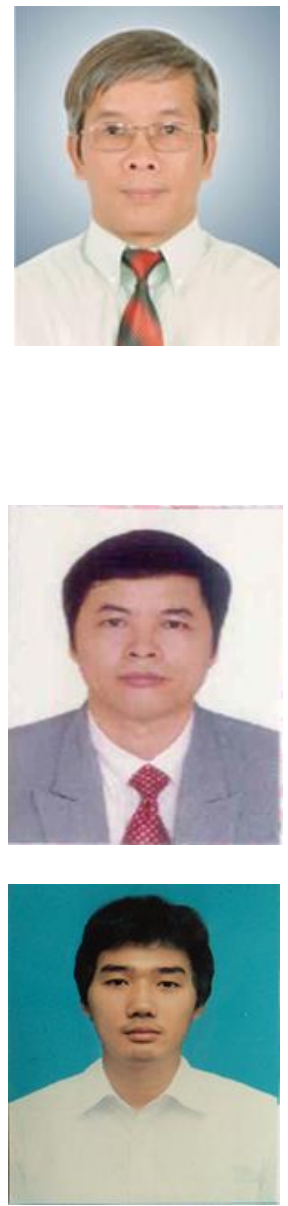

Nguyen Phung Quang received his Dipl.-Ing. (Uni.), Dr.-Ing. and Dr.-Ing. habil. degrees from TU Dresden, Germany in 1975, 1991 and 1994 respectively. Prior to his return to Vietnam, he had worked in Germany industry for many years, contributed to create inverters REFU 402 Vectovar, RD500 (REFU Elektronik); Simovert 6SE42, Master Drive MC (Siemens). From 1996 to 1998, he served as lecturer of TU Dresden where he was conferred as Privatdozent in 1997. He joined Hanoi University of Science and Technology in 1999, as lecturer up to now. He is currently a professor of HUST and honorary professor of TU Dresden. He was author/co-author of more than 170 journal and conference papers; 8 books with three among them was written in German and one in English entitled "Vector Control of Three-Phase AC Machines - System Development in the Practice" published by Springer in 2008, and 2nd edition in June 2015. His Research Interests are Electrical Drive Systems, Motion Control, Robotic Control, Vector Control of Electrical Machines, Wind and Solar Power Systems, Digital Control Systems, Modeling and Simulation.

Nguyen Nhu Hien received the B.S. degree in electrical engineering from Bac Thai University of Mechanics and Electrics (former name of Thai Nguyen University of Technology) in 1976, the M.S degree and the $\mathrm{PhD}$ degree in automation and control from Ha Noi University of Science and Technology in 1997 and 2002 respectively. He is currently a Associate Professor with Automation Division, Faculty of Electrical Engineering, Thai Nguyen University of Technology. His current research interests include advance control of multi-axis drive system, control for multi-variable processes and renewable energy systems.

Nguyen Thanh Binh received the B.S and M.S degree in control engineering and automation from Hanoi University of Science and Technology (HUST), Viet Nam, in 2014 and 2017. Since 2018, He is currently with University of Ulsan as PhD student. His research interests include Control of land, air, underwater vehicles, Robotic Systems, Adaptive Dynamic Programming and Robust Nonlinear Model Predictive Control. 